\title{
TREATMENT OF REACTIONS IN LEPROSY BY AQUEOUS SULPHETRONE INJECTIONS AND ORAL INH IN A RURAL CENTRE
}

\author{
V. Ekambaram, m.B., B.S., \\ State Leprosy Officer and Director of the Govt. Leprosy \\ Treatment and Study Centre, Tirukoilur \\ and \\ C. S. Ganghadhara Sharma, B.m., B.S., \\ Civil Surgeon, Govt. Leprosy Treatment and \\ Study Centre, Tirukoilur
}

\section{Introduction}

We aim in this paper to present the results of our study of the treatment of reaction states in leprosy using injections of $50 \%$ aqueous solution of Sulphetrone and oral INH daily. We also studied a few cases not in reaction who were treated with this therapy.

It is worth while defining Reaction states in leprosy. CochranE thinks that reaction in leprosy is a local or systemic response to the release of bacilli or bacillary products into the tissues. NELSON Souza Campos and P. Rath de Souza say that the term "lepra reaction" is used in a general way by many authors to describe a class of quite different clinical and pathological processes. They point out that when the term is used in the general sense it comprises 3 main groups: (1) the classical lepra action, which means a syndrome similar to that of erythema nodosum, e. multiforme, e. exudativa, etc., and this e.n. syndrome is peculiar to lepromatous type of leprosy; (2) reactional tuberculoid leprosy, which some authors call "tuberculoid lepra reaction", including the transitional lesions; (3) outbreaks of acute reactivation and exacerbation of the disease, which can occur in any of its clinical forms, and the list of clinical forms of reaction shows how varied they are in their pathogenesis.

They go on to classify lepra reaction of the classical variety into 2 sub-groups, namely Progressive Lepra Reactions and Ervthema Nodosum Leprosum (ENL), which occur in the lepromatous type, and the exact nature of the reaction, whether allergy or para-allergy, is not yet understood clearly. The ENL type of reaction includes the reactional tuberculoid leprosy and the transitional lesions, of which the Borderline type is the best example. Tuberculoid reaction is of the nature of an acute exacerbation of the disease occurring in any of the clinical forms of leprosy.

In our therapeutic study we directed attention mainly to the 2nd and 3rd varieties of lepra reaction as described above. СосH- 
CLINICAL RESULTS OF TREATMENT WITH AQUEOUS SULPHETRONE PARENTERALY AND INH ORALLY A. of Patients in a Reactive State

1. Before Treatment

Date: December 1959

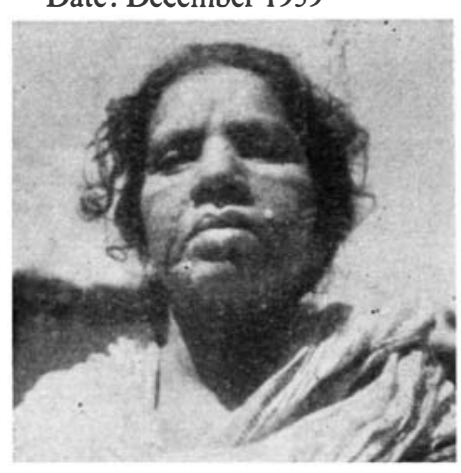

3. Before Treatment Date: $3-9-58$

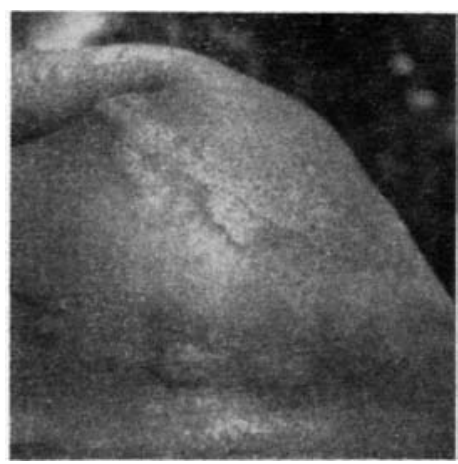

1. After Treatment

Date: $18-6-60$

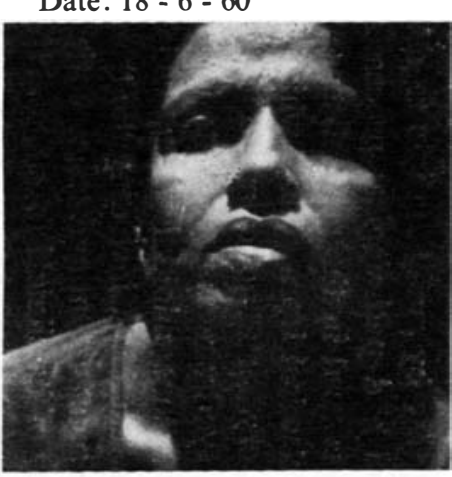

3. After Treatment

Date: $4-11-58$

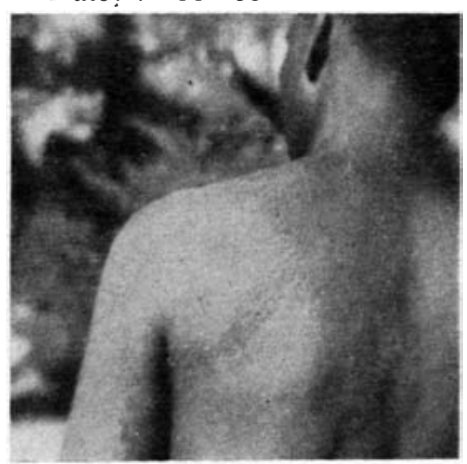

2. Before Treatment

Date: 3 - 9 - 58

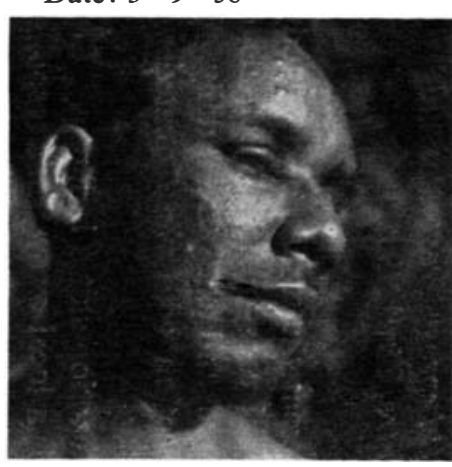

4. Before Treatment Date: $17-8-58$

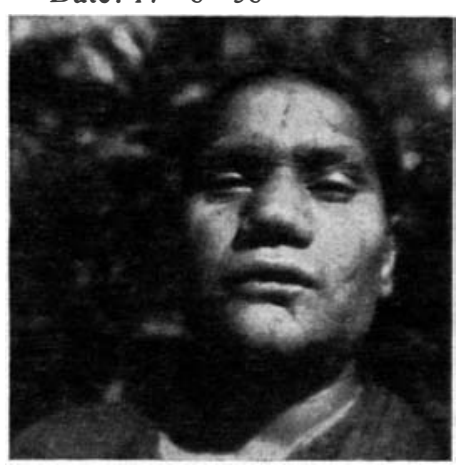

2. After Treatment Date: 4 - 11 - 58

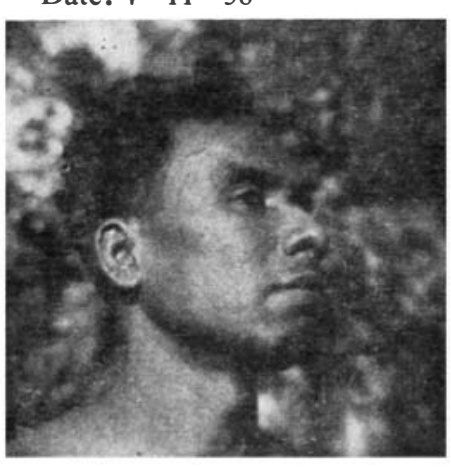

4. After Treatment Date: $4-10-58$

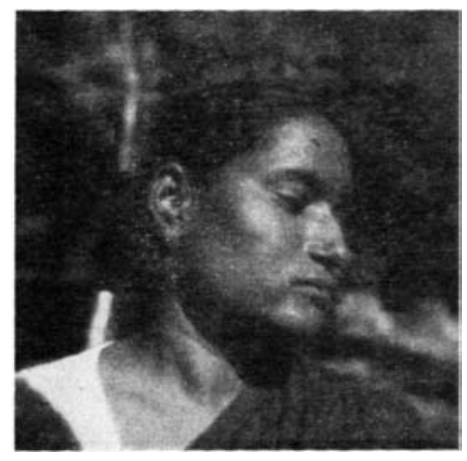


RANE described tuberculoid reaction as the manifestation of an acute tissue response to prevent the attempt of the bacilli to penetrate the skin and nerve barrier. In reactional tuberculoid he states that every lesion shows an acute reaction phase, whereas in a tuberculoid reaction, if there are several lesions, some of them are quiescent. The borderline type is itself a state of reaction, even though it can react further, with local and constitutional disturbances. To treat reactional states in leprosy has always been a problem, because their nature has not been fully understood. Empirically corticosteroids, antimalarial drugs, and antimony compounds have found to be of use. Cochrane, writing on the treatment of reaction states in tuberculoid and borderline leprosy states that these are cases of active tissue defence, and that sulphones or other therapy must be stopped immediately, as the reaction in these types of leprosy often results in healing of the condition. He gives worning also of the danger of nerve damage, with resultant deformity. Yet the only treatment advised by him is palliative, i.e. drugs such as aspirin and phenacetin to relieve pain.

Souza Campos and Rath de Souza say also that tuberculoid reaction may lead to severe nerve involvement and consequent trophic changes, and point out that this may be insidious, and without marked change in the size of the nerve. In reactional tuberculoid leprosy and in borderline leprosy there may be similar difficulties. H. J. WHEATE prefers to treat reactional states on thiosemicarbazones, rather than on the sulphones. In our experience we have not got satisfactory results in reaction states in leprosy by treatment on the lines suggested by COCHRANE, or by small doses of sulphones, or on thiosemicarbazones. There is great need for some specific therapy for reactional states which would improve the condition without damage to the nerves, in a short period of time. The aggravated reactional macules do not improve the appearance of the patient, so in addition to the danger to nerves there is this cosmetic factor, which interferes with leprosy campaigns by introducing a factor which militates against free social contacts by the patients and causes time off work, etc.

We have made trial of the sulphetrone - INH drug combination. We had previously found the injection of $50 \%$ aqueous sulphetrone safe, effective and cheap. It was suitable for even debilitated patients, and in reactions more suitable than the parent sulphones. DAvisON reported not too favourably on INH, but V. EKAMBARAM studied it during his tour of Thailand as a WHO Fellow and formed a better opinion of it, especially in reacting cases.

\section{Methods and Dosage}

It was decided to give parenteral aqueous Sulphetrone $(50 \%)$ in a dose of $0.5 \mathrm{ml}$. daily and add to this orally $150 \mathrm{mg}$. daily of $\mathrm{INH}$ 
5. Before Treatment Date: $17-8-58$

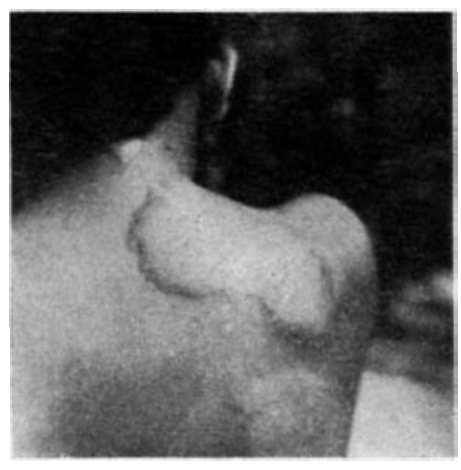

Before Treatment Date: $28-1-59$

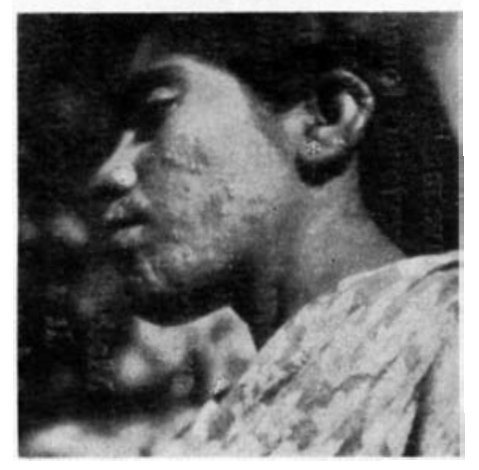

5. After Treatment

Date: $6-11-58$

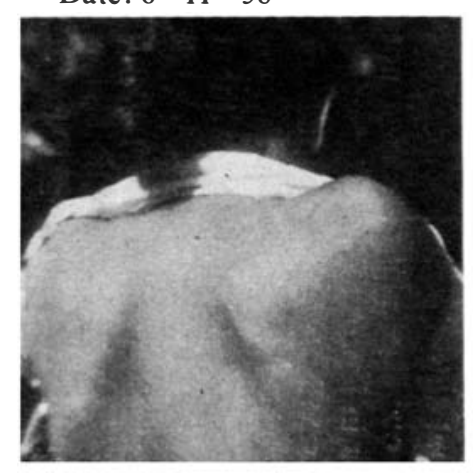

\section{B. of Patients in a Non-Reactive State}

1. After Treatment Date: $13-3-60$

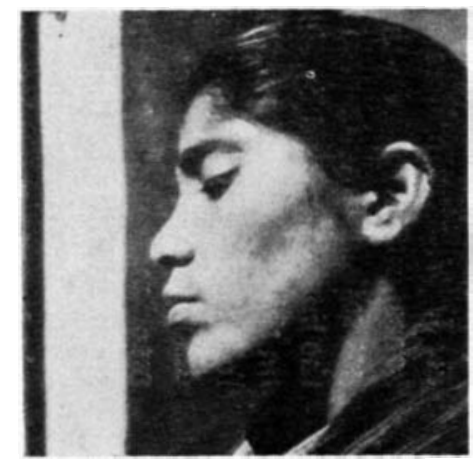

6. Before Treatment

Date: $30-7-58$

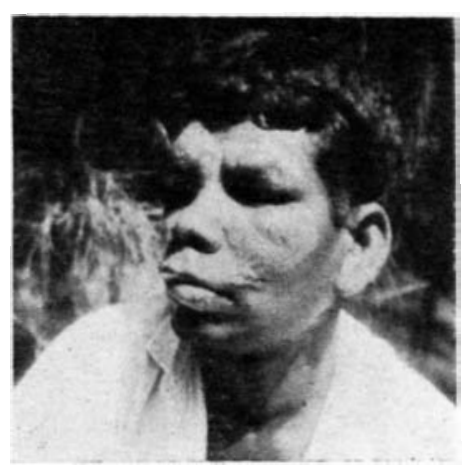

6. After Treatment

Date: August 1958

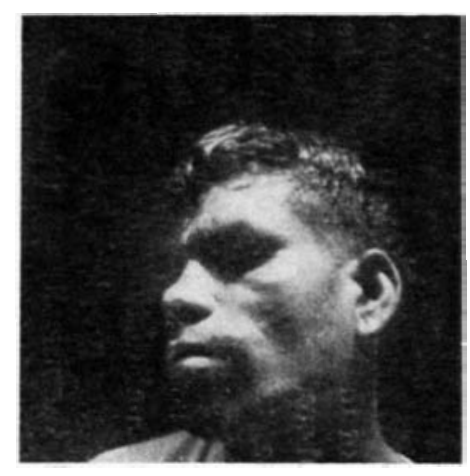

2. After Treatment Date: $13-3-60$
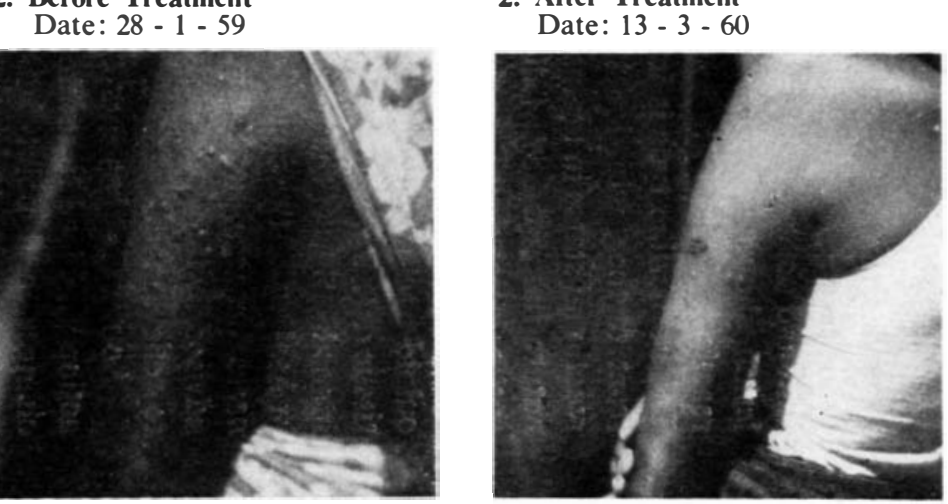
Results of Treatment (Patients in Reacting State 1958 and 1959-Annexure-I)

\begin{tabular}{|c|c|c|c|c|c|c|c|c|c|}
\hline \multirow{2}{*}{$\begin{array}{c}\text { Total } \\
\text { number } \\
\text { of patients }\end{array}$} & \multirow{2}{*}{$L$. } & \multicolumn{3}{|c|}{ Types of reactive patients } & \multirow{2}{*}{$\begin{array}{l}\text { Number } \\
\text { improved } \\
\text { clinically } \\
\text { with } \\
\text { reduction of } \\
\text { reaction }\end{array}$} & \multirow{2}{*}{$\begin{array}{c}\text { Number } \\
\text { not } \\
\text { improved }\end{array}$} & \multirow{2}{*}{$\begin{array}{l}\text { Number } \\
\text { in whom } \\
\text { nerve damage } \\
\text { developed } \\
\text { during } \\
\text { treatment }\end{array}$} & \multirow{2}{*}{$\begin{array}{c}\text { Average number } \\
\text { of days required } \\
\text { for subsidence of } \\
\text { reaction in } \\
\text { T.M. and } \\
\text { R.T.L. }\end{array}$} & \multirow{2}{*}{$\begin{array}{c}\text { Average number } \\
\text { of days for } \\
\text { subsidence of } \\
\text { lesions of } \\
\text { Borderline } \\
\text { cases }\end{array}$} \\
\hline & & T.M. & R.T.L. & Borderline & & & & & \\
\hline 9 & Nil & 5 & 3 & 1 & 7 & 1 & Nil & 45 days & 90 days \\
\hline
\end{tabular}

ANNEXURE-II

(a) Patients not in a state of reaction in 1958 and 1959-remarks about results of treatment

Total number of cases started

$$
\begin{array}{ccc}
\text { Type } & \multicolumn{2}{c}{\text { analysis of these cases }} \\
\text { Lep. } & \text { T.M. } & \text { INDT. } \\
3 & 2 & 1
\end{array}
$$


(in 3 doses of $50 \mathrm{mg}$.). The therapy was continued even in the face of mild pyrexia, but was stopped for raised pyrexia or signs of nerve involvement. Otherwise it was kept up even after the reactive phase subsided. As regards choice of cases, in the beginning of the trial only reactive cases unsuitable for sulphone therapy or those who did not improve with thiosemicarbazone were selected, but as the trial progressed and the results were found satisfactory, we added a few lepromatous and non-lepromatous cases not in a state of reaction. The total number of cases chosen was 20 , of whom only 5 discontinued treatment. There were 9 patients in a reactive phase and 6 non-reactive. The duration of treatment was 2, 3, 5, 6, 13 and 24 months in 1958 and 1959.

\section{Results}

These were good in reactive cases. The therapy could be described as potent and specific, and the reaction was controlled without any danger to the nerves. The reactive macules subsided within a month or so, and oedema and erythema subsided, and the macules seldom persisted beyond 2 months. Neuritis and pyrexia also cleared up. Days of hospitalization were reduced and the patient became normal and fit for his daily occupation in a relatively short period.

The non-reactive lepromatous cases were not immune from lepra reaction. Patient " $M$ " had 2 reactions during the 4 months of treatment, and "Miss $\mathrm{K}$ " had 4 reactions during 18 months.

In non-reactive tuberculoid cases the clinical improvement under this treatment seemed to be quicker than with the ordinary sulphone treatment. The lesions flatten, but further improvement is not satisfactory, the general clinical and bacteriological improvement not really being appreciably better.

In non-reactive lepromatous cases, the clinical and bacteriological is slow and the new treatment is not recommended.

\section{References}

1. Cochrane, R. G., "Leprosy in Theory and Practice" (1959). Reactions in Leprosy on p. 00.

2. WheATE, H. W. (July, 1957).

3. Davison, A. S., Lep. Rev. (July, 1955).

4. Nelson Souza Campos and P. Rath de Souza, Int. J. of Lep. (July-Sept., 1934).

\section{Acknowledgement}

Our grateful thanks are due to Dr. K. Ramanujam, M.B., B.S., Medical Officer, Silver Jubilee Clinic, Saidapet, Madras, for his valuable suggestions and advice in the preparation of this article. 